\title{
Epidemiological Trends in Search and Rescue Incidents Documented by the Alpine Club of Canada From 1970 to 2005
}

\author{
Gwynn M. Curran-Sills, MSc, MD; Amalia Karahalios, MPH, PhD \\ From the Department of Family Medicine, University of Calgary, Calgary, Alberta, Canada (Dr Curran-Sills); and the Department of \\ Biostatistics, Melbourne School of Population and Global Health, University of Melbourne, Melbourne, Victoria, Australia (Dr Karahalios).
}

\begin{abstract}
Objective.-To provide a descriptive review of the epidemiology of search and rescue (SAR) incidents across Canada as documented in the Alpine Club of Canada (ACC) database.

Methods.-A retrospective, cross-sectional review of SAR reports collected by the ACC with incidents dating from January 1, 1970 to June 12, 2005, was analyzed.

Results.-The ACC database contained 1088 incidents with 1377 casualties. Casualties had 944 (68.6\%; 95\% CI, 64.2 to 73.1) injuries or illness, and 433 (31.4\%; 95\% CI, 28.6 34.6) fatalities. Males accounted for $76.1 \%$ of all casualties and $82.3 \%$ of the fatalities when sex was reported. A bimodal distribution of casualties was seen, with the peaks around February and August. Hiking and mountaineering resulted in more than half of all casualties that yielded any type of morbidity, whereas mountaineering and skiing, ski mountaineering, or snowboarding accounted for almost two thirds of all fatalities. Human error and slips and falls were the major contributors to the presumptive cause of incidents. The lower limb was the most common anatomic location of traumatic injury, accounting for $41.6 \%$ (95\% CI, 37.6 to 45.9) of these injuries. Hypothermia, exhaustion, frostbite, and dehydration represented the majority of all nontraumatic conditions. British Columbia and Alberta accounted for $91.6 \%$ (95\% CI, 86.0 to 97.5$)$ of the incidents in the database.

Conclusions. - The study serves to illustrate trends in SAR epidemiology that may be encountered by SAR personnel within British Columbia and Alberta. Furthermore, it highlights the need for additional Canadian-based studies to better understand this area of prehospital medical encounters.
\end{abstract}

Key words: prehospital, search and rescue, epidemiology, public safety

\section{Introduction}

The medical aspect of search and rescue (SAR) in Canada is a poorly understood element of prehospital care. There are two Canadian epidemiological studies that examined the morbidity and fatality associated with SAR incidents. One focused on mountain SAR operations in Banff, Yoho, and Kootenay National Parks ${ }^{1}$ and found that musculoskeletal injuries account for the majority of these incidents. The second study reviewed 272 medical action reports from the Canadian Forces Search and Rescue Technician program during a 4-year period $^{2}$ and indicated that trauma-related cases were predominant. However, both studies underscore the

Corresponding author: Gwynn M. Curran-Sills, MSc, MD, Family Medicine and Primary Care Research Office, University of Calgary G012, Health Sciences Centre 3330 Hospital Drive NW Calgary, Alberta T2N 4N1 (e-mail: gwynn.curran.sills@utoronto.ca). typical array of medical conditions seen in any hospital setting are also being encountered during SAR missions. Their restricted geographic range and their small sample size limit these studies, respectively.

To date there are no provincial or national level investigations that analyze the epidemiology of SAR incidents in Canada. In an effort to widen our understanding of these patterns, this study has examined the SAR reports collected by the Alpine Club of Canada (ACC). Further insight into the epidemiology of SAR incidents is beneficial to all stakeholders involved in the medical care of these individuals. This includes SAR teams, emergency medical service personnel, and hospital healthcare professionals. Beyond medical relevance, expanding our knowledge of these trends is of value to the outdoor recreational tourism industry. Ultimately, an objective understanding of these patterns will contribute to evidence-based risk 
analysis, prevention strategies, and best-practice recommendations.

\section{Methods}

This study was a retrospective, cross-sectional review of the SAR incident database maintained by the ACC from January 1, 1970, until June 12, 2005. The ACC does not conduct SAR operations but does collect information on incidents from multiple sources as shown in Table 1. The database was initially populated through archival searches of ACC literature and self-reporting by ACC members. This process of data collection expanded to include information from personnel affiliated with the organizations outlined in Table 1. The ACC also created an online format for data acquisition through their website. For each SAR incident, the ACC collected the following: accident ID, date, route $\mathrm{ID}$, description of event, analysis of event, cause, rescue mode, number of injured, injury description, number of fatalities, location, information source, and type of activity. For unknown reasons the database has not been formally maintained since June 12, 2005.

The characteristics of the ACC database are shown in Table 1, along with the exclusion criteria. The following definitions were used: Incident was an event that led to the creation of one or more casualties; casualty was a person who sustained any type of morbidity or fatality; injury was any condition due to a traumatic mechanism of injury; and illness was all other conditions not related to traumatic mechanism of injury. To organize the information contained in the ACC database, it was sometimes necessary to group similar terms for a given variable. This process was applied to the following variables: data source, mode of extraction by rescue personnel, activity undertaken during the incident, presumptive cause of the incident, anatomic location of the traumatic injury, and types of nontraumatic illness. Specific definitions have been provided for presumptive cause of the incident, anatomic location of the traumatic injury, and types of nontraumatic illness within their respective figures or tables. The proximity to the nearest urban center for a given incident was based on the shortest linear distance between 2 points. An incident may have included multiple victims; the term casualty captured this and represented the sum of victim(s) who sustained any type of morbidity or fatality. The aforementioned variables were described by presenting frequencies and percentages with the corresponding 95\% CI. Microsoft Excel version 12.3.6 for Mac (Microsoft Corp, Redmond, WA) and Stata v13.1 (StataCorp LP, College Station, TX) was used for this analysis, along with ArcGIS (Esri, Redlands, CA). The University of Calgary Research Ethics Board (REB13-0815) gave approval for this study.

\section{Results}

The ACC database contained 1088 incidents with 1377 casualties (Table 1). Of these casualties, 944 (68.6\%; 95\% CI, 64.2 to 73.1) suffered an injury or illness and 433 (31.4\%; 95\% CI, 28.6 to 34.6) were fatalities. Age data were available for $523(38.0 \%$; $95 \% \mathrm{CI}, 34.8$ to 41.4) of the casualties. Sex data were available for 1032 (74.9\%; 95\% CI, 70.4 to 79.7) of all casualties. When sex was reported, males accounted for $76.1 \%$ of all casualties and $82.3 \%$ of the fatalities (male fatalities were

Table 1. The characteristics of the Alpine Club of Canada dataset

\begin{tabular}{|c|c|c|}
\hline$\overline{\text { Category }}$ & Frequency & Percentage \\
\hline Incidents in ACC database & 1422 & 100.0 \\
\hline Incidents excluded & 334 & 23.5 \\
\hline $\begin{array}{l}\text { Injury reported as "none," } \\
\text { "unknown," "miscellaneous," } \\
\text { "no injury," "not indicated," } \\
\text { "unspecified injury," } \\
\text { "missing" }\end{array}$ & 307 & 21.6 \\
\hline $\begin{array}{l}\text { Date of incident before } \\
\text { January } 1,1970^{a}\end{array}$ & 25 & 1.8 \\
\hline Duplicate records & 2 & 0.1 \\
\hline Incidents analyzed & 1088 & 76.5 \\
\hline \multicolumn{3}{|l|}{ Casualties with the following data } \\
\hline Morbidity & 944 & 68.6 \\
\hline Fatality & 433 & 31.4 \\
\hline Sex & 1032 & 74.9 \\
\hline Age & 523 & 38.0 \\
\hline Sex and age & 448 & 32.6 \\
\hline Total casualties analyzed & 1377 & 100.0 \\
\hline \multicolumn{3}{|c|}{ Information sources for the ACC Database } \\
\hline Parks Canada & 313 & 28.8 \\
\hline Government $^{b}$ & 291 & 26.7 \\
\hline Media & 194 & 17.8 \\
\hline $\begin{array}{l}\text { Canadian climbing or skiing } \\
\text { community }\end{array}$ & 102 & 9.4 \\
\hline Self report & 68 & 6.3 \\
\hline Alpine Club of Canada & 51 & 4.7 \\
\hline SAR teams & 28 & 2.6 \\
\hline Provincial park & 24 & 2.2 \\
\hline Emergency medical services & 8 & 0.7 \\
\hline Unknown & 4 & 0.4 \\
\hline Royal Canadian Mounted Police & 3 & 0.3 \\
\hline Military & 1 & 0.1 \\
\hline Outdoor school & 1 & 0.1 \\
\hline Total & 1088 & 100.0 \\
\hline
\end{tabular}

\footnotetext{
${ }^{a}$ The decision to exclude data before January 1, 1970, was based on the extremely limited data before this time.

${ }^{b}$ Emergency Management British Columbia contributed data from 1999 to 2005, except for 2003 provincial incidents.
} 


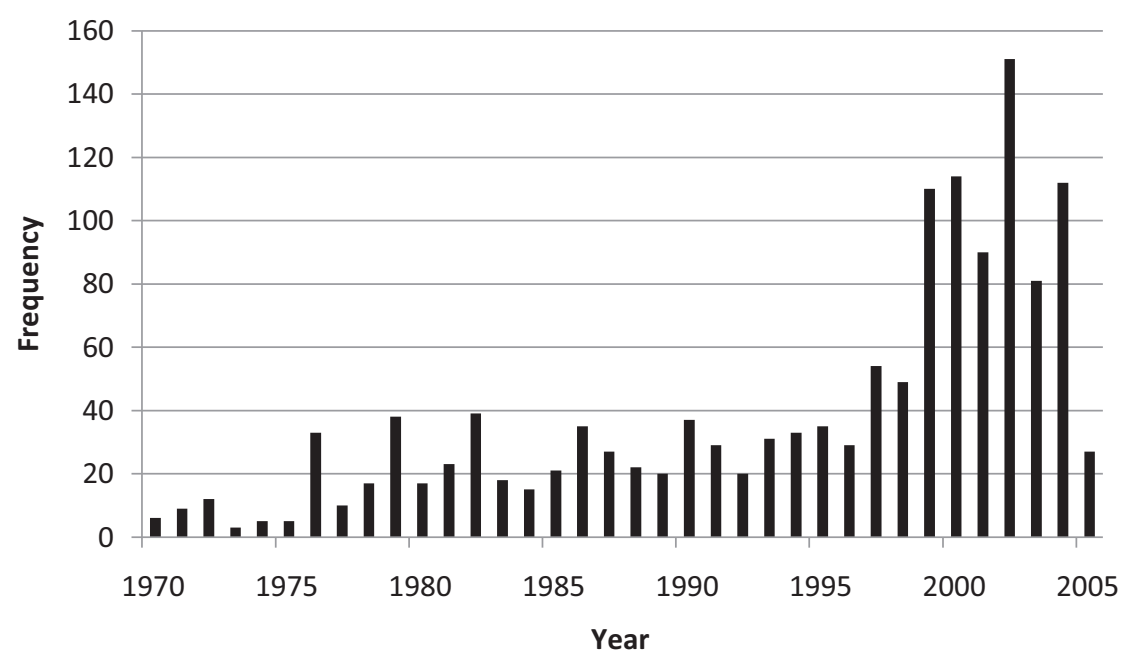

Figure 1. The frequency of casualties by year as reported within the Alpine Club of Canada database from January 1970 to June 2005.

$4.8[95 \% \mathrm{CI}, 4.3$ to 5.5$]$ times higher than female fatalities). Figure 1 displays the number of casualties as a function of year and shows a stark increase in the number of casualties in 1999 and subsequent years. On a monthly basis there was a bimodal distribution of casualties with peaks in February (the winter peak was smaller) and August (Figure 2). Ground personnel (49.7\%; 95\% CI, 46.0 to 53.4$)$ and helicopter $(37.4 \%$; $95 \%$ CI, 34.2 to 40.8 ) rescue were the predominant modes of extracting casualties. For helicopter extractions, ground personnel were also involved and ground SAR groups participated in $87.1 \%$ of all incidents (Table 2). Mountaineering (29.3\%; 95\% CI, 26.5 to 32.3 ) and hiking (27.0\%; 95\% CI, 24.3 to 29.9 ) resulted in more than half of all casualties that yielded any type of morbidity, whereas mountaineering $(34.9 \%$; $95 \%$ CI, 29.5 to 40.9) and skiing, ski mountaineering, or snowboarding (27.9\%; 95\% CI, 23.2 to 33.4$)$ accounted for nearly two thirds of all fatalities (Table 3 ). Human error and slips and falls were the major contributors to the presumptive cause of incidents (Figure 3). The lower limb was the most common anatomic location of traumatic injury, accounting for $41.6 \%$ (95\% CI, 37.6 to 45.9$)$ of these injuries (Table 4). Hypothermia $(49.4 \%$; $95 \%$ CI, 41.8 to 57.8 ), exhaustion (18.7\%; $95 \%$ CI, 14.2 to 24.2 ), frostbite $(11.0 \%$; $95 \%$ CI, 7.6 to 15.3$)$, and dehydration (7.4\%; 95\% CI, 4.7 to 11.1 ) accounted for the majority of all nontraumatic illness. Data were obtained from across

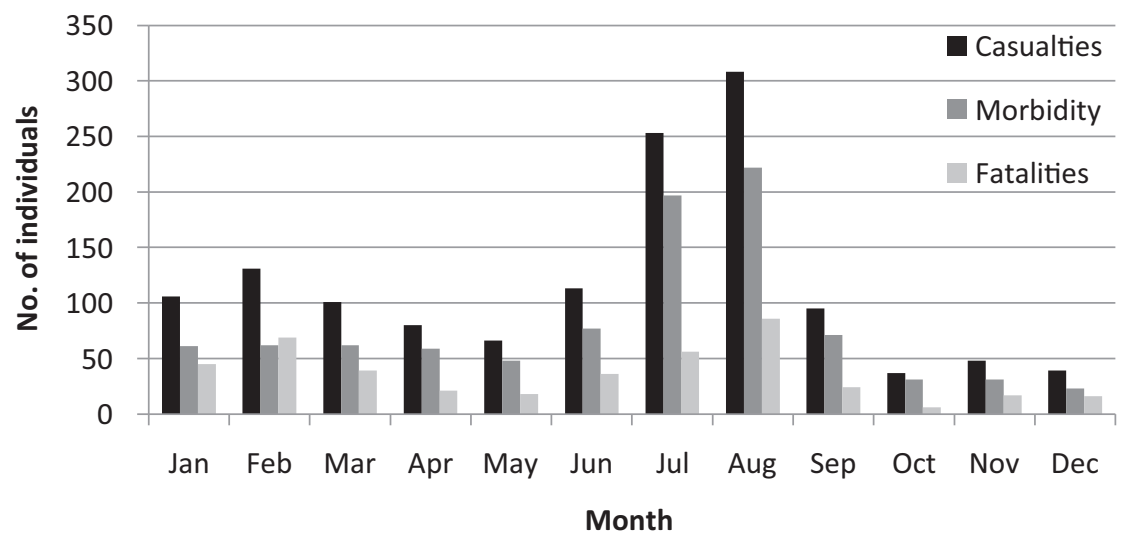

Figure 2. The distribution of casualties, morbidity, and fatalities by month as reported within the Alpine Club of Canada database from January 1970 to June 2005. Casualties (blue bars): males 788 (57.2\%), females 247 (17.9\%), unknown sex 342 (24.8\%). Morbidity (red bars): males 517 (54.8\%), females 191 (20.2\%), unknown sex 236 (25\%). Fatalities (green bars): males 271 (62.6\%), females 56 (12.9\%), unknown sex 106 (24.5\%). 
Table 2. The mode of extraction by rescue personnel as reported within the Alpine Club of Canada database from January 1970 to June 2005

\begin{tabular}{|c|c|c|c|c|}
\hline Rescue mode & Incidents (\%) & Casualties (\%) & Morbidity (\%) & Fatalities (\%) \\
\hline Ground personnel & $560(51.5)$ & $684(49.7)$ & $531(56.3)$ & $153(35.5)$ \\
\hline SAR & $326(30.0)$ & $399(29.0)$ & $333(35.3)$ & $66(15.2)$ \\
\hline Park warden & $107(9.8)$ & $133(9.7)$ & $75(7.9)$ & $58(13.4)$ \\
\hline Self-rescue & $72(6.6)$ & $86(6.2)$ & $83(8.8)$ & $3(0.7)$ \\
\hline EMS & $23(2.1)$ & $24(1.7)$ & $20(2.1)$ & $4(0.9)$ \\
\hline Passerby & $18(1.7)$ & $22(1.6)$ & $18(1.9)$ & $4(0.9)$ \\
\hline Police & $14(1.3)$ & $20(1.5)$ & $2(0.2)$ & $18(4.2)$ \\
\hline Helicopter & $398(36.6)$ & $515(37.4)$ & $339(35.9)$ & $176(40.6)$ \\
\hline Unknown & $128(11.8)$ & $176(12.8)$ & $72(104)$ & $104(24.0)$ \\
\hline Tour boat & $1(0.1)$ & $1(0.1)$ & $1(0)$ & $0(0)$ \\
\hline Canadian Coast Guard & $1(0.1)$ & $1(0.1)$ & $1(0)$ & $0(0)$ \\
\hline Total & $1088(100)$ & 1377 (100) & $944(100)$ & $433(100)$ \\
\hline
\end{tabular}

Note: The denominator for the percentage calculation is the total that corresponds for each section.

Canada with the exception of Prince Edward Island, Saskatchewan, and the Northwest Territories (Figure 3). British Columbia and Alberta accounted for 91.6\% (95\% CI, 86.0 to 97.5 ) of the incidents in the database. The closest urban centers with the highest incident rates were Vancouver and Golden in British Columbia and Banff, Canmore-Kananaskis, and Jasper in Alberta (Figure 4).

\section{Discussion}

The bimodal distribution of incidents in February and August was likely related to the usage of the mountain environments for winter and summer sports and activities. A similar trend was observed in the study by Wild. ${ }^{1}$

Although challenging to interpret given the missing data (as seen in Figure 2), males accounted for $76.1 \%$ of all casualties and $82.3 \%$ of all fatalities when sex data were available. Despite this limitation, Wild ${ }^{1}$ reported a similar rate of fatalities among men, but a lower rate of male casualties $(63.1 \%)$. Two American studies that examined wilderness SAR in New Hampshire during a 3 -year period ${ }^{3}$ and a 10 -year review of SAR incidents in Yosemite National Park $^{4}$ reported male casualties accounted for $64.5 \%$ and $62.0 \%$, respectively. The Yosemite National Park $^{4}$ findings and a study conducted in Pima, Arizona, that reviewed SAR incidents during a 13 -year period ${ }^{5}$ reported that male fatalities accounted for $85.9 \%$ and $87.0 \%$, respectively. However, it should be underscored that the settings for these American studies would be considered different than the Canadian Rocky Mountains or coastal British Columbia and may not be representative.

Table 3. The activity undertaken during an incident as reported within the Alpine Club of Canada database from January 1970 to June 2005

\begin{tabular}{|c|c|c|c|c|c|c|c|c|}
\hline Activity & $\begin{array}{c}\text { Incident } \\
(\%)\end{array}$ & $\begin{array}{c}\text { Casualties } \\
(\%)\end{array}$ & $\begin{array}{c}\text { Morbidity }^{a} \\
(\%)\end{array}$ & $\begin{array}{c}\text { Male } \\
\text { morbidity }\end{array}$ & $\begin{array}{c}\text { Female } \\
\text { morbidity }\end{array}$ & $\begin{array}{c}\text { Fatalities }^{b} \\
(\%)\end{array}$ & $\begin{array}{c}\text { Male } \\
\text { fatalities }\end{array}$ & $\begin{array}{c}\text { Female } \\
\text { fatalities }\end{array}$ \\
\hline Hiking & $304(27.9)$ & $372(27.0)$ & $302(32.0)$ & 106 & 113 & $70(16.1)$ & 41 & 17 \\
\hline Mountaineering & $292(26.8)$ & $403(29.3)$ & $252(26.7)$ & 158 & 20 & $151(34.9)$ & 92 & 12 \\
\hline Rock climbing & $193(17.7)$ & $210(15.2)$ & $173(18.3)$ & 127 & 26 & $37(8.5)$ & 30 & 5 \\
\hline $\begin{array}{l}\text { Skiing, ski mountaineering, } \\
\text { or snowboarding }\end{array}$ & $143(13.1)$ & $213(15.5)$ & $92(9.7)$ & 38 & 17 & $121(27.9)$ & 65 & 19 \\
\hline Ice climbing & $100(9.2)$ & $116(8.4)$ & $86(9.1)$ & 63 & 11 & $30(6.9)$ & 23 & 1 \\
\hline Scrambling & $53(4.9)$ & $60(4.4)$ & $38(4.0)$ & 24 & 4 & $22(5.0)$ & 18 & 2 \\
\hline Snowshoeing & $3(0.3)$ & $3(0.2)$ & $1(0.1)$ & 1 & 0 & $2(0.5)$ & 2 & 0 \\
\hline Total & $1088(100)$ & 1377 (100) & $944(100)$ & 517 & 191 & 433 (100) & 271 & 56 \\
\hline
\end{tabular}

\footnotetext{
${ }^{a}$ The sex data for morbidity are present for $1035(75.2 \%)$ casualties.

${ }^{b}$ The sex data for fatality are present for $327(75.5 \%)$ casualties.
} 


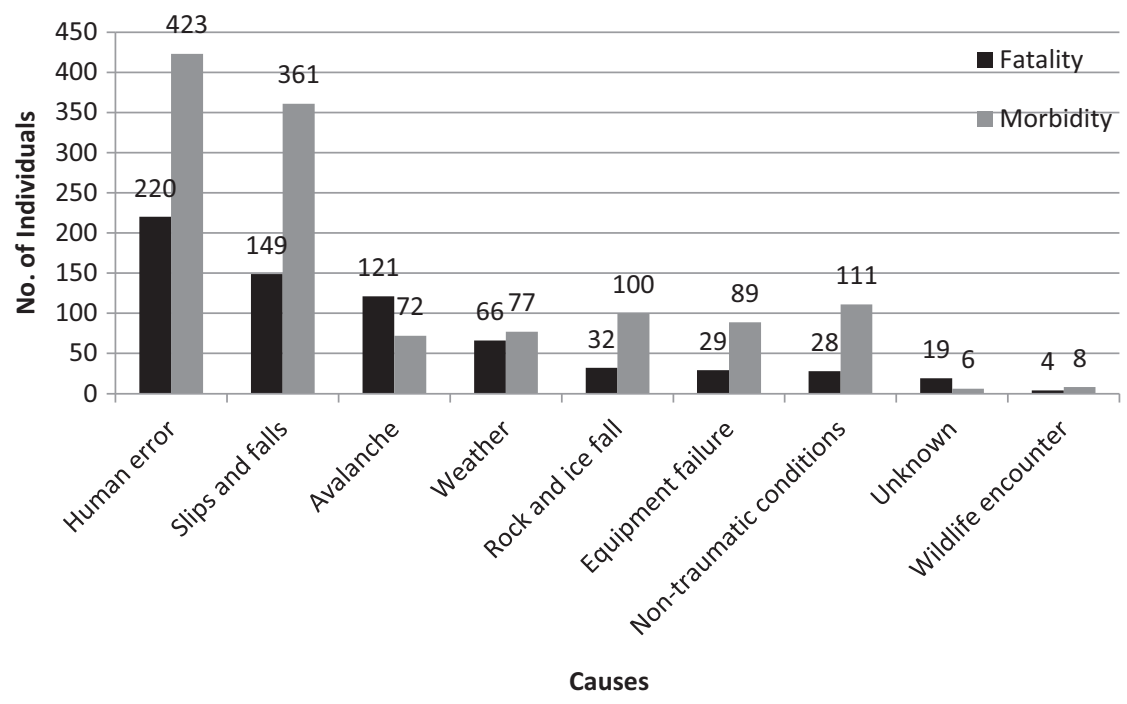

Figure 3. The presumptive cause of an incident as reported within the Alpine Club of Canada database from January 1970 to June 2005 . Multiple causes were typically attributed to each incident. Definition for the causes are as follows: human error (solo activity, inadequate or lacking equipment, technique, ability, and navigation); slips and falls (casualty fall into or on crevasse, water, ice, rock, snow, or object); equipment failure (anchor, knot, protection, and rope failure); and nontraumatic conditions (please see Table 4, types of nontraumatic morbidity, for all conditions included in this definition).

Ground SAR personnel were used in $87.1 \%$ of all incidents, and a helicopter (in conjunction with ground SAR personnel) was necessary in just over one third of all incidents. Within North America, the use of helicopters during SAR activities ranges from $2.5 \%$ to $64.0 \%,{ }^{1,3,4}$ although a study from the Mont-Blanc region of the French Alps documents helicopter use in $95 \%$ of incidents. ${ }^{6}$ This observation underscores the differences in geography and the regional response culture that can be seen in other areas of North America and Europe.

Activities that are typically considered to be high risk, for example, mountaineering, skiing, ski mountaineering, and snowboarding, accounted for $62.8 \%$ of the fatalities. The latter of these 2 categories occurred outside of commercial ski resort boundaries and is not afforded the safety net that can be found in ski resort areas. Hiking contributed to only $32.0 \%$ of nonfatal incidents, whereas in the study by Wild it accounted for $43.5 \%$, and American studies reported $52.0 \%$ to $55.0 \%$.,6

Not surprisingly, the lower limb was the most common anatomic location for traumatic injury, accounting for $41.6 \%$ of injuries, in keeping with literature from the United States, ${ }^{3,7}$ France, ${ }^{6}$ and Scotland. ${ }^{8}$ As is expected when encountering casualties in the outdoor environment, hypothermia, exhaustion, frostbite, and dehydration represented a significant proportion of all nontraumatic illnesses. However, the other nontraumatic presentations in Table 4 accounted for approximately
$13 \%$ of incidents and highlights the importance of ground SAR personnel having to contend with a diverse set of medical encounters. The Canadian ground SAR community is trying to standardize the technical training received by individuals working in these organizations. The information presented in this study and other Canadian-based studies may help to guide the development of this curriculum from a medical standpoint.

\section{Limitations}

The data contained in the ACC incident reports are limited in a variety of ways. As the ACC focuses on the alpine environment, there is a predilection toward incidents that occur in mountainous regions and, in particular, the Rocky Mountains range. At the reporting level, incidents have been gathered by multiple organizations over the years, with no systems in place for corroborating events or checking the completeness of reporting. Within individual reports, there are frequent gaps in data, especially related to the age and sex of casualties. Medical information is recorded from multiple sources with mixed levels of medical trainingbystanders, first-aiders, first-responders, or medical professionals-and a level of inconsistency was considered to be inherent as there was no reference to a final diagnosis. Finally, the reported incidents are not correlated with the total population that pursues outdoor 


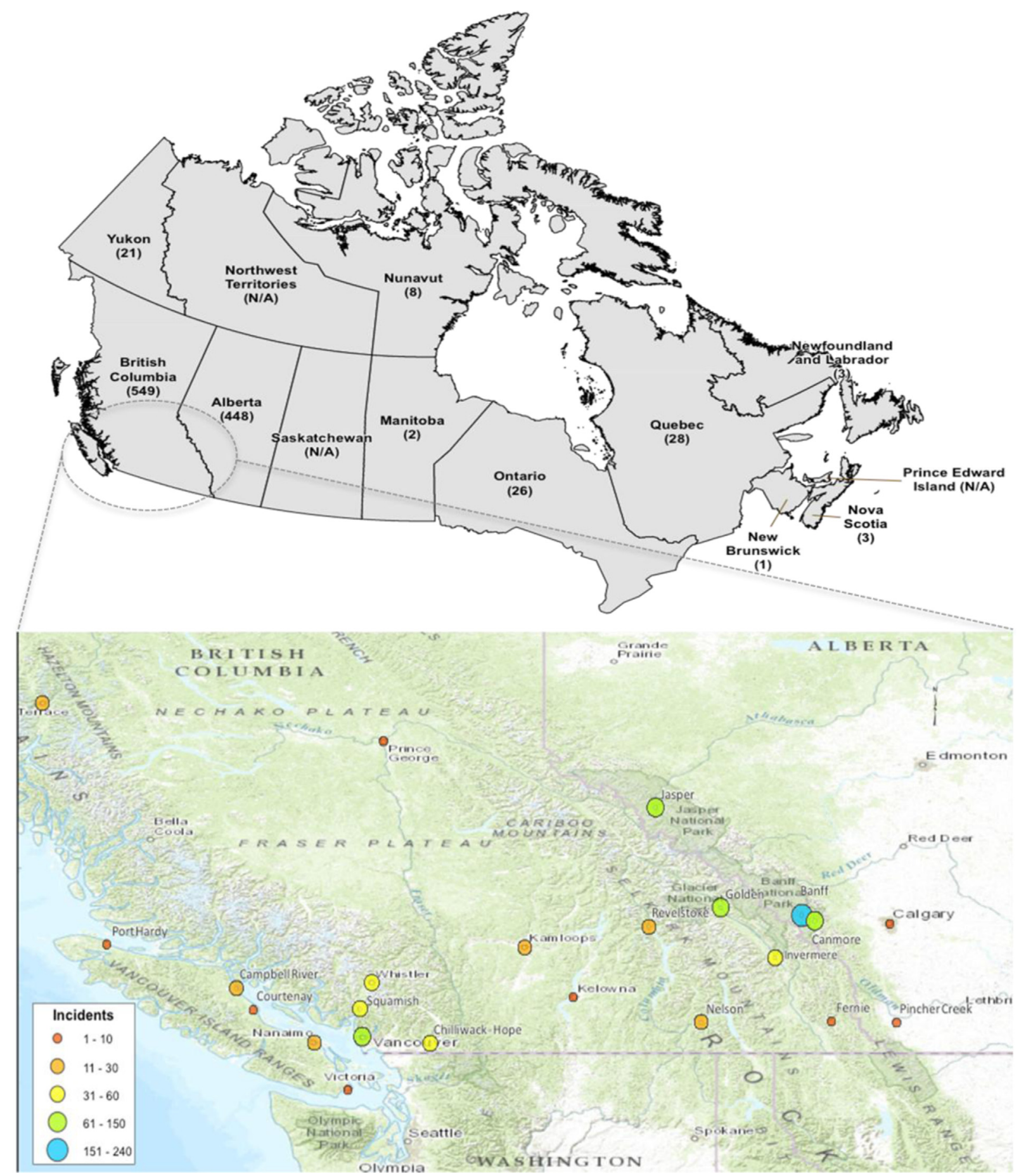

Figure 4. The distribution of incidents by Canadian province as reported within the Alpine Club of Canada database from January 1970 to June 2005. Provinces or territories with no data are indicated by N/A.

recreation within a given region or during a specific time frame. As a result of these limitations, the findings should not be considered representative but instead may only portray a subset of the outdoor recreationist population.
Because of the study design, a cross-sectional methodology, no associations could be derived between exposures and outcomes. Given the inability to establish a well-defined population (inconsistent demographic data) and the large number of possible risk factors (leading to 
Table 4. The types of morbidity as reported within the Alpine Club of Canada database from January 1970 to June 2005

\begin{tabular}{|c|c|c|}
\hline Injury category & Frequency & Percentage \\
\hline \multicolumn{3}{|l|}{ Traumatic injury location $^{a}$} \\
\hline Lower limb & 396 & 41.6 \\
\hline Head & 138 & 14.5 \\
\hline Upper limb & 135 & 14.2 \\
\hline Thorax & 106 & 11.1 \\
\hline Superficial injuries $^{b}$ & 74 & 7.8 \\
\hline Spine and neck & 69 & 7.2 \\
\hline Pelvic & 27 & 2.8 \\
\hline Abdomen & 8 & 10.8 \\
\hline Total & 953 & 100 \\
\hline \multicolumn{3}{|l|}{ Nontraumatic illnesses } \\
\hline Hypothermia & 153 & 49.4 \\
\hline Exhaustion & 58 & 18.7 \\
\hline Frostbite & 34 & 11.0 \\
\hline Dehydration & 23 & 7.4 \\
\hline Decreased level of consciousness ${ }^{c}$ & 13 & 4.2 \\
\hline Neurologic symptoms ${ }^{d}$ & 10 & 3.2 \\
\hline Respiratory distress ${ }^{e}$ & 6 & 1.9 \\
\hline Abdominal pain & 4 & 1.3 \\
\hline Cardiac arrest & 3 & 1.0 \\
\hline Chest pain & 3 & 1.0 \\
\hline Dizziness & 1 & 0.3 \\
\hline Electrocution & 1 & 0.3 \\
\hline Toxic ingestion & 1 & 0.3 \\
\hline Total & 310 & 100 \\
\hline
\end{tabular}

Note: Casualties did experience multiple injuries or illness; a total of 659 and 285 casualties had traumatic and nontraumatic morbidity, respectively.

${ }^{a}$ Traumatic injuries to a specific region include fracture, soft tissue injury, abrasion, bruising, lacerations, and unspecified injury to that region.

${ }^{b}$ Superficial injuries refer to unspecified lacerations, abrasions, or bruises.

${ }^{c}$ Decreased level of consciousness refers to disorientation, unconscious, or diabetic coma.

${ }^{d}$ Neurologic symptoms refer to seizure, stroke, visional disturbance, paresthesia, paralysis, or loss of fine motor control.

${ }^{e}$ Respiratory distress refers to pneumonia, embolism, pulmonary edema, or asthma exacerbation.

the need for a stratified analysis), it was believed that a retrospective analytic methodology could not be used. However, accessing better quality data sets in the future may allow investigations to examine potential relationships between risk factors (demographic, outdoor activity, region of the country, etc) and the likelihood of injury, illness, or death.

Figure 1 highlights the fluctuations that are present in the ACC data and underscores the difficulty when trying to interpret trends as a function of time, in particular the increase in casualties that occurred in 1999 and subsequent years. This was related to a new information source being added to the ACC database, ie, the British Columbia Search and Rescue reports became available online. Beyond this there are relatively large swings in the number of casualties between 1975 and 1999 on an almost cyclical basis for which the authors do not have a clear explanation. Given the manner in which data were collected by the ACC, it is likely that a selection bias was inherent.

\section{Conclusions}

The study serves to illustrate trends that may be encountered by SAR personnel within British Columbia and Alberta. This study also highlights the need to identify or create a data set that meets more robust standards and from which good quality epidemiology can be derived. Barring the creation of Canadian-focused SAR epidemiology, it is conceivable that using American-based studies would be appropriate and would assist in guiding Canadian SAR organizations. If we take, for example, the SAR operations occurring in British Columbia and Alberta, this likely shares more in common with trends that would be witnessed in Washington, Idaho, or Montana than it would with the Canadian Prairies, Arctic, or Atlantic Coastal regions. However, a number of federal, provincial, and regional level agencies are involved in SAR activities and may operate databases that could be used to further explore the geographic and seasonal variations of Canadian SAR operations.

\section{Acknowledgments}

We would like to thank the Alpine Club of Canada and, in particular, Edwina Podemski and Ernst Bergman for their assistance with accessing the database and understanding its content. Tapan Talavlikar was an asset with the construction of the GIS map.

\section{References}

1. Wild FJ. Epidemiology of mountain search and rescue operations in Banff, Yoho, and Kootenay National Parks, 2003-06. Wilderness Environ Med. 2008;19:245-251.

2. Popplow JR. A review of Canadian Forces Search and Rescue operations was conducted for the period of 1991 . Aviat Space Environ Med. 1993;67:486-490.

3. Ela GK. Epidemiology of wilderness search and rescue in New Hampshire, 1999-2001. Wilderness Environ Med. 2004;15:11-17.

4. Hung EK, Townes DA. Search and rescue in Yosemite National Park: a 10-year review. Wilderness Environ Med. 2007;18:111-116. 
5. Goodman T, Iserson KV, Strich H. Wilderness mortalities: a 13-year experience. Ann Emerg Med. 2001;37:279-283.

6. Stephens BD, Diekema DS, Klein EJ. Recreational injuries in Washington state national parks. Wilderness Environ Med. 2005;16:192-197.
7. Marsigny B, Lecoq-Jammes F, Cauchy E. Medical mountain rescue in the Mont-Blanc massif. Wilderness Environ Med. 1999;10:152-156.

8. Hearns S. The Scottish mountain rescue casualty study. Emerg Med J. 2003;20:281-284. 